\title{
Perception of Destiny in Turkey: An Investigation through the Psychology and Sociology Disciplines
}

Veysel Mehmet Elgin' (elgin v@ibu.edu.tr), Nahide Konak², Ibrahim Biri²

1Department of Psychology, Bolu Abant Izzet Baysal University, Bolu, Turkey

2Department of Sociology, Bolu Abant Izzet Baysal University, Bolu, Turkey

\section{Introduction}

The perception of destiny is an important topic that affects people's psychological processes, and this effect is salient in the daily lives of people living in Turkey.

\section{Objective}

This study aims to examine the perception of a form of destiny -"kısmet" [in Turkish]- in daily life in Turkey within the framework of both Psychology and Sociology disciplines.

\section{Methods}

- Paper-pencil study.

- Demographic Questions and Open-ended questions

(e.g., Perception of kısmet, Usage/Expression of kısmet,(when, reasons, frequencies, etc.).

Participants: 100 undergraduates (89 women, 9 men, 2 unspecified) at an Anatolian university ( $M_{\text {age }}=22.24$, $\left.S D_{\text {age }}=2.90\right)$

- Content analysis was performed.

\section{Findings and Conclusion}

It was revealed that "kısmet" is a central issue in Turkey and having multi-layered perceptions: Main Categories: Foreordination/Predestination, God (\& Trust in God), Marriage (\& Prospective Partner). When: Interpreting/Construing the events (especially negative events, romantic relationships), Hoping positive things to occur (\& giving hope to others), Frequently.

Function: Pragmatic function [providing mental and emotional tranquility], Religious belief, Habits. Some Quotes: "It [kısmet] is fated to happen", "[kısmet is] waiting what will happen", "I use it [kısmet] when I think or talk about marriage and prospective partner,", "[kısmet is] acceptance, relief", "I use "kısmet' when I want something to happen", "I use 'kısmet' when I say let it be", "I use 'kısmet' as the habit of using a certain expression", "I believe 'kısmet' has a sort of narcosis effect on people", "it [kısmet] is escape [from uncertainty]", "it [usage of kısmet] relieves people and prevents from thinking hard".

i) Kısmet reflects the cultural characteristics of collectivistic culture such as low independence, connectedness and harmony,

ii) Kısmet fulfills the psychological needs such as security, control, reduction of ambiguity, reduction of cognitive burden, construction of meaning and psychological relief,

iii) Kısmet is also related with social psychological mechanisms such as self regulation, external attribution, locus of control, and system justification,

iv) Kısmet is highly related with religion,

v) Based on Weberian sociological social action theory kısmet has multiple use: (a) traditional action: habit, (b) value-rational action: beliefs in religion and predestination, and (c) means-end rational action: stopping unwanted conversation. 